\title{
At the coalface
}

\section{For whom the bells knell}

Michael Heim, Tully Steinbach Orthopaedic Rehabilitation Department, Sheba Medical Center, Israel, affiliated to the Sackler School of Medicine, University of Tel Aviv.

\section{Authors' abstract}

A 72-year-old widowed woman known to have an organic brain syndrome was hospitalised owing to gangrene of her lower limbs. The gangrene had been caused by an adduction contracture of her hip resulting in pressure on the medial surface of her left leg. In addition she had pressure sores over both trochanters and the sacrum. The smell of putrefication could be sensed from a distance and on examination large white worms could be seen slithering in the decomposing tissue. The patient was pyrexial, oblivious of her surroundings, and without pain. Surgery - limb amputations - would not restore the patient to a cognitive state nor improve here quality of life, but abstinence posed an inherent threat of sepsis, and revulsion to the attendants. The sacral pressure sore was so large that surgical closure was impossible. The question of surgical intervention is discussed.

\section{Case history}

A 72-year-old widow was delivered to the emergency room by the owner of a private nursing home. He claimed that the patient's mental state had altered in the last day and that she was unresponsive. The patient was admitted for examination and was found to be in a coma responding only to painful stimuli. The patient's only family, her son, lived abroad and was immediately notified of his mother's condition and requested to come to his mother's bedside. The relevant facts of the patient's history were gained from the son and the nursing home owner. Four years previously the patient had been totally independent, living on her own, and had fallen and broken her left hip. She had undergone surgery and a hip prosthesis had returned her to her previous independent state. Three years later she fell and broke her right hip. At that stage an organic mental syndrome was diagnosed from information gained from her neighbours and from assessment while in hospital. Her neighbours informed the hospital staff that for at least half a year before the present fall the patient had been housebound and that friends had been providing basic assistance. In hospital it was decided that this old lady required nursing care and

\section{Key words}

Incompetent patients; dementia; care of the aged; treatment decisions. without surgery the patient was sent to a geriatric institution for conservative orthopaedic management of the fracture and thereafter rehabilitation. The patient remained in this institution for eight months but never became ambulant. She developed an adduction contracture of the hip and was later discharged to the private nursing home whence she came to the emergency room.

On examination the patient responded only to painful stimuli. Her two legs were bandaged as were both her trochanteric areas and her sacrum. A most terrible smell was present and when the bandages were removed worms could be seen moving within the necrotic tissues. The patient was pyrexial $\left(39^{\circ} \mathrm{C}\right)$ and had a haemoglobin of $8.6 \mathrm{G}$ per cent.

The patient's electrolyte imbalance was corrected, a blood transfusion given and her mental state returned to its previous reduced level of function. She recognised her son and was able to answer questions about incidents in her past but was completely disorientated for time and place. After two weeks of treatment the patient underwent above knee amputation of the left leg and repair of the left trochanteric pressure sore. The wounds healed and after three weeks the sutures were removed.

This small emaciated lady remained with an enormous sacral pressure sore that extended over both sides of the buttock and thus precluded any surgical intervention.

The patient was discharged to a nursing home and died two weeks later.

\section{Discussion}

From time immemorial there has been a cognisant deliberate separation between the living and the dead. The African elephant in the wild has by nature disposed of its dead as have other species. Whether the dead have been buried, burnt on a pyre, cremated or embalmed, ancient custom has demanded the division between the living and the non-living. When this divergence takes place between totally independent creations the ordinance is preserved; however, when these opposing states occur within the same, singular, organism a physiological dichotomy develops. The involvement of vital structures within the deceased area ultimately leads to the demise of the organism. 
However, when appendages have undergone devitalisation they may remain attached to the viable areas. With time the physiological process will sever the devitalised area by a cleavage. This process is protracted, the cleavage plane often being involved in additional complications which alter the nature of the natural pathophysiology. Surgeons, the protagonists of this cleavage process, have traditionally encouraged the timely and complete separation of the living from the devitalised. This sine qua non heralded the advent of amputations as the modus in the management of peripheral gangrene (1). Accepting that this treatment comprises the 'state-of-the-art' in management of ischaemic limb necrosis one questions whether the surgical procedure should be carried out without consideration of the patient as a whole, or whether an option exists and surgical denial is feasible when considering the medical (practical and theoretical) and moral issues.

Ischaemic limbs, even when dependent and at rest, cause the most common presenting symptom: the patient's inability to find an acceptable solution to the intense pain. The origin of this pain is neural ischaemia which is situated proximally to the devitalised tissues which are totally anaesthetic. Necrotic tissues challenge the body image, affronting two of the basic senses; smell and sight. The unsuppressable, nauseating, offensive odour permeating from the suppurating tissues are objectionable to the patient as is the altered colour and configuration of the area. Should the devitalised area remain uninfected then the visual evidence in association with excruciating pain encourages the patient to seek medical assistance.

The only effective treatment is the extirpation of the necrotic area. Where this process, no matter how complicated, will substantially alter the prognosis and quality of life there is no doubt that every possible effort should be made to enhance a successful outcome. A dilemma arises when surgery will neither alter the prognosis nor substantially change the quality of life. 'The individual has a right to choose death with appropriate safeguards. . . . It is the rights of persons that are sacred - not the rights of professions or ideologies' (2). A tremendous amount of literature is available with respect to withholding or withdrawing life prolonging treatment $(3,4,5)$ and even euthanasia has been discussed (6). The decision whether actively to treat or actively abstain is dependent upon moral and medical criteria. The concept of 'lovable decisions' with regard to re-humanising dying are excellently discussed by Stollerman (7) and Sorenson (8).

Providing that the individual is compos mentis no persons or authorities may impose their will upon the patient. The problem arises when the mental faculties of the sick are impeded and the direction of the therapeutic modalities require the consent of another person. That transfer of responsibility, guardianship, is a formal act requiring legal sanction wherein the rights of decision-making are conveyed to a third party or group of doctors. The guardians are usually concerned about two aspects; the maintenance of the individual's dignity and the ensuring of complete pain palliation.

Within a hospital environment both these aspects may usually be ensured. However, within the bounds of geriatric auxiliary care these two aspects cannot always be guaranteed, particularly the former.

Medical research has made leaps and bounds; in all spheres there exists a constant search for the new and the more effective. Unfortunately too little attention and too late is being focused on the quality of life of the geriatric disabled, leading to instances where one questions whether medical servitude is morally correct in protracting the patient's existing hell. During the battle of Waterloo Napoleon's surgeon introduced the concept of 'triage' where 'priority of treatment should be weighted towards persons who can make significant gains from the therapy' (9). Have we surgeons yet come to terms with our personal Waterloo?

Michael Heim MB ChB is Orthopaedic Consultant in the Orthopaedic Rehabilitation Department, Sheba Medical Center, Tel Hashomer, Hospital. Tully Steinbach MD is the Director of the Orthopaedic Rehabilitation Department which is affiliated to the Sackler School of Medicine at the University of Tel Aviv, Israel.

\section{Editor's note}

At the coalface is a new series in which readers relate o ethical dilemma they have experienced themselves in this. course of their work. The journal is keen to publish such reports and any reader wishing to contribute should send his or her paper (of not more than 1500 words) to the Editor, Journal of Medical Ethics, IME Publications, 151 Great Portland Street, London WIN SFB. Contributions can be published anonymously if the writer wishes.

\section{References}

(1) Gilles L. Hippocrates's precepts in amputations. New York: Griene and Stratton, 1954: 8.

(2) Corbett T E. Withholding or withdrawing life-prolonging medical treatment. Fournal of the American Medical 3 Association 1986; 256:2673.

(3) Bedell S E, Pelle D, Maher P L, et al. Do-not-resuscitate orders for critically ill patients in the hospital: How are they used and what is their impact? Fournal of the American Medical Association 1986; 256:233-237.

(4) Newman R G, Meyer K, Mernick M. The dilemma of donot-resuscitate orders. New York State journal of medicine N 1986;86:1-2.

(5) Withholding or withdrawing life-prolonging medical $\mathrm{N}$ treatment. Opinion of the American Medical Association. N Council of Ethical and Judicial Affairs. Fournal of the $\sigma$ Missouri State Medical Association 1986; 27:221.

(6) Sagel J. Voluntary euthanasia. Lancet 1986;2:691.

(7) Stollerman G. Lovable decisions: re-humanizing dying. $\$$ Fournal of the American Geriatric Society 1986; 34:172-:

(8) Sorenson J. The character of love to guide re-humanizing $\frac{\overrightarrow{0}}{\mathrm{D}}$ dying. Fournal of the American Geriatric Society 1987;

(9) Nickel V. Triage in orthopaedic rehabilitation. New York: $\frac{\mathbb{Q}}{\sigma}$ Churchill Livingstone, 1982: 6-7. 